\title{
Intravenous Dexamethasone Prolongs the Analgesic Effect of Caudal Bupivacaine after Hypospadias Repair Surgery
}

\author{
Wesam A. Abo Elwafa, Amr A. Zakaria*, Abdelrahman H. Abdelrahman, Wael A. Mahmoud \\ Department of Anaesthesia and Intensive Care, Faculty of Medicine, Sohag University \\ *Corresponding author: Amr A Zakaria, Mobile: (+20) 01004423431, E-Mail: amrsalam381@gmail.com
}

\begin{abstract}
Background: Dexamethasone has a powerful anti-inflammatory action and has been demonstrated to reduce morbidity after surgery.

Objective: The aim of this study was to examine the effects of a single i.v. dose of dexamethasone in combination with caudal block on postoperative analgesia in children.

Patients and methods: Sixty pediatric patients (aged 2-10 years) undergoing hypospadias repair surgery were included in this prospective, randomized, double-blinded study at Sohag University Hospital. After induction of general anaesthesia, children received either dexamethasone $0.5 \mathrm{mg} / \mathrm{kg}$ (maximum $10 \mathrm{mg})(\mathrm{n}=30)$ or the same volume of saline $(\mathrm{n}=30)$ i.v. A caudal anaesthetic block was then performed using $1 \mathrm{ml} / \mathrm{kg}$ of bupivacaine $0.25 \%$ in all patients.

Results: After surgery, rescue analgesic consumption, pain scores, and adverse effects were evaluated for $24 \mathrm{~h}$. The time to first administration of acetaminophen (rescue analgesia) was significantly longer in the dexamethasone group ( $11.35 \pm 2.36 \mathrm{hr}$ vs $8.75 \pm 1.33 \mathrm{hr})$ with a significant value of 0.01 . Total amount of the analgesia required (paracetamol) was significantly lower in dexamethasone plus caudal block group than the caudal block alone (430 $\mathrm{mg}$ vs $680 \mathrm{mg}$ ) respectively.

Conclusion: Postoperative pain scores were lower in the dexamethasone group and the incidence of adverse effects was similar in both groups. Intravenous dexamethasone $0.5 \mathrm{mg} / \mathrm{kg}$ in combination with a caudal block augmented the intensity and duration of postoperative analgesia without adverse effects in children undergoing hypospadias repair surgery.
\end{abstract}

Keywords: Dexamethasone, Bupivacaine, Hypospadias Repair Surgery.

\section{INTRODUCTION}

A caudal block is a popular reliable and safe technique for pediatric pain management after infraumbilical surgical procedures. It is by far the most commonly used regional anesthesia technique. It is a good, reliable and easy method to provide perioperative analgesia in a variety of pediatric surgery ${ }^{(\mathbf{1}, 2)}$. However, it has the disadvantage of short duration of action and a significant proportion of patients; despite face moderate to severe pain as the block resolve ${ }^{(\mathbf{1})}$.

Dexamethasone is a corticosteroid hormone with powerful anti-inflammatory as well as analgesic property. Its administration through epidural route has been shown to reduce the incidence and severity of postoperative pain in adults ${ }^{(3)}$ and improved morbidity such as nausea, vomiting, fever and delayed oral intake, in children ${ }^{(4)}$.

Systemic administration of steroids suppresses tissue levels of bradykinin and the release of neuropeptides from nerve endings. It also inhibits synthesis of cyclooxygenase- 2 in peripheral tissues and in the central nervous system resulting in a reduction in prostaglandin production, which contribute to enhanced nociception in inflamed tissue ${ }^{(5,6,7)}$. Dexamethasone administration through intravenous (IV) route along with caudal block has been shown to significantly reduce severity of pain and rescue analgesic requirement in the post-operative period ${ }^{(8)}$.
Paracetamol, a low molecular weight phenol compound, is another analgesic widely used for pediatric postoperative pain. Its efficacy depends on the route and dose of administration. Benefits are greater when it is given through the intravenous route in contrast to oral or rectal forms ${ }^{(9)}$.

The goal of this study was to evaluate the efficacy of a single dose of intravenous dexamethasone in combination with caudal block as regards the augmentation of the intensity and duration of postoperative analgesia after hypospadias repair surgery.

\section{PATIENTS AND METHODS}

This prospective cohort study design was employed at Sohag University Hospital. 60 ASA status I and II pediatric patients aged 2 to 9 years and underwent hypospadias repair surgery were prospectively enrolled in this study.

Children having any contraindication for caudal blocks such as known allergy to local anesthetic agents, coagulation disorders, preexisting neurological disorders, any systemic or local infection, and anatomical abnormalities of the spine were excluded from the study. Also, children having other coexisting diseases such as diabetes mellitus, cardiovascular or respiratory problems, history of convulsions, psychiatric disorders, mental retardation and failed caudal block were excluded from the study. 
Anesthesia was induced by face mask with sevoflurane and oxygen. In older children, i.v. cannula was inserted and propofol $2 \mathrm{mg} / \mathrm{Kg}$ was used in induction, the trachea was intubated with the use of rocuronium $0.5 \mathrm{mg} / \mathrm{Kg}$ and the lungs were ventilated by controlled ventilation. Anesthesia was maintained (through Datex Ohmeda S/5 Aespire anaesthesia machine) with isoflurane (1.0-2.0\%) using standard monitoring.

After induction of anaesthesia, caudal block was performed (using a $5 \mathrm{~cm}$ short beveled $22 \mathrm{G}$ caudal needle) in the lateral decubitus position. After identifying the space, using the loss of resistance technique with saline, children received $1.5 \mathrm{ml} / \mathrm{kg}$ bupivacaine $0.25 \%$ (maximum volume, $20 \mathrm{ml}$ ) freshly prepared.

\section{Children were allocated randomly into one of two groups for caudal block:}

- Group 1 (Dexamethasone group): Patients received intravenous dexamethasone $0.5 \mathrm{mg} / \mathrm{kg}$ (maximum 10mg) and caudal block by bupivacaine $0.25 \%$ (1mglkg)

- Group 2 (control group): Patients were received caudal block by bupivacaine $0.25 \%(1 \mathrm{mg} \backslash \mathrm{kg})$ and the same volume intravenous normal saline.

All blocks were performed by the same anaesthesiologist throughout the study. The time of caudal block was recorded, and the surgery was allowed to begin 15 min after performing the block. Standard monitoring was used (Nihon Koden monitor) during anesthesia and surgery. Heart rate and blood pressure was recorded before induction and every 5 min until the end of surgery.

During surgery, adequate analgesia was defined by hemodynamic stability, as indicated by the absence of an increase in heart rate (HR) or systolic arterial pressure (SAP) of more than $20 \%$ compared with baseline values obtained just before the surgical incision, with isoflurane concentration maintained at approximately 1.0-2.0\% MAC. Bradycardia, defined as a $20 \%$ decrease in HR compared with preoperative values, was treated with atropine $0.01 \mathrm{mg} / \mathrm{kg}$ i.v. Hypotension, defined as a $20 \%$ decrease in SAP compared with preoperative values, was treated with the use ephedrine 1-2 mg i.v. If HR or SAP are increased by more than $20 \%$, analgesia will be considered inadequate, and the child received rescue opioid during operation (Fentanyl $1 \mathrm{mic} / \mathrm{kg}$ ).

If more than $35 \%$ from the preoperative baseline, study was considered to be failed. Anesthesia was discontinued when the wound dressing had been applied and the endotracheal tube extubated. In the ward: Monitoring of hemodynamic state (MAP and HR), with assessment of analgesia and development of any side effects until $24 \mathrm{~h}$ after caudal block. Analgesia assessment was made by using the pediatric observational Face/ Leg/ Activity/ Crying /
Consolability (FLACC) pain scale with its $0-10$ score range (10). Each child was assessed upon arrival in the ward, every $1 / 2 \mathrm{~h}$ for the first $2 \mathrm{~h}$ and then every $2 \mathrm{~h}$ for $12 \mathrm{~h}$.

The primary outcome of this study i.e., the mean time to first rescue analgesic (time interval between a caudal block to the recording of FLACC pain score > 4) was recorded. FLACC scale is a measurement used to assess pain of children or patients who are unable to communicate their pain. Each category is scored on the $0-2$ scale, which results in a total score of $0-10.0$ represents relaxed and comfortable, $1-3$ represents mild discomfort, 4-6 represents moderate pain and 7-10 represents severe discomfort or pain or both. Rescue analgesia was provided with IV paracetamol $(20 \mathrm{mg} / \mathrm{kg})$ if FLACC score > 4. Secondary outcomes such as total doses of rescue analgesic (paracetamol) and adverse effects such as post-operative nausea and vomiting, respiratory depression (fall in $\mathrm{SpO}_{2}$ of $<92 \%$ requiring supplementary $\mathrm{O}_{2}$ ), hypotension (fall in the blood pressure $>20 \%$ of the baseline value) and bradycardia (HR below 60 beats/min) were looked for and recorded.

\section{Ethical approval}

Local Ethical Committee of Sohag University Hospital approved the study and informed parental consents were obtained.

\section{Statistical analysis}

Data were checked and cleaned manually for completeness and then coded and entered into sciences (IBM-SPSS), version 20 IBM- Chicago, USA, which was used for statistical data analysis. Data expressed as mean, standard deviation (SD), number and percentage. Mean and standard deviation were used as descriptive value for quantitative data. Chi square test was used to compare the qualitative data between the two groups, and student $t$ test was used to compare the means between the two groups. The sample size done using sixty patients, 30 in each group to avoid any drop in patients during the study.

\section{RESULTS}

This interventional randomized controlled study was carried out in Sohag University Hospital, Department of Anesthesia and Intensive Care. 60 pediatric patients who were going to undergo a hypospadias repair surgery were included in the study. To compare data of the two groups, all data were represented as mean and standard deviation (SD). Mean and standard deviation were used as descriptive value for quantitative data. Chi square test was used to compare the qualitative data between the two groups and student $t$ test was used to compare the means between the two groups.

60 patients were enrolled in the study, age, sex, height, body weight, and duration of surgery were almost homogenous with no significant differences between the groups (Table 1). 
Table (1): Demographic and perioperative characteristics of hypospadias surgery pediatric patients

\begin{tabular}{|l|c|c|c|c|c|}
\hline Variable & $\begin{array}{c}\text { Dexamethasone } \\
\text { Group }\end{array}$ & $\begin{array}{c}\text { Control } \\
\text { Group }\end{array}$ & Test & P & Sig \\
\hline Age (year) & 5.2 & 5.5 & Z=0.77 & $\mathbf{0 . 4 4}$ & NS \\
\hline Height (cm) & $\mathbf{8 9 . 7 5} \pm 4.58$ & $\mathbf{8 6 . 3 5} \pm 4.77$ & $\mathbf{t}=\mathbf{2 . 3 0}$ & $\mathbf{0 . 6 2}$ & NS \\
\hline Body Weight (kg) & $\mathbf{2 0 . 5 5} \pm 2.21$ & $\mathbf{2 0 . 1 0} \pm 2.31$ & $\mathbf{t}=\mathbf{0 . 6 3}$ & $\mathbf{0 . 5 3}$ & NS \\
\hline BMI & $\mathbf{2 5 . 1 0} \pm 2.42$ & $\mathbf{2 5 . 0 5} \pm 1.93$ & $\mathbf{t}=\mathbf{0 . 7 6}$ & $\mathbf{0 . 9 4}$ & NS \\
\hline $\begin{array}{l}\text { Duration of } \\
\text { surgery(min) }\end{array}$ & $\mathbf{5 9 . 2 ( 1 4 . 2 )}$ & $\mathbf{5 7 . 1}(13.7)$ & $\mathbf{t}=\mathbf{0 . 8 0}$ & $\mathbf{0 . 6 3}$ & NS \\
\hline
\end{tabular}

As regards the intraoperative hemodynamic parameters, there were no statistically significant differences in pulse (fig. 1) and mean arterial blood pressure (fig. 2).

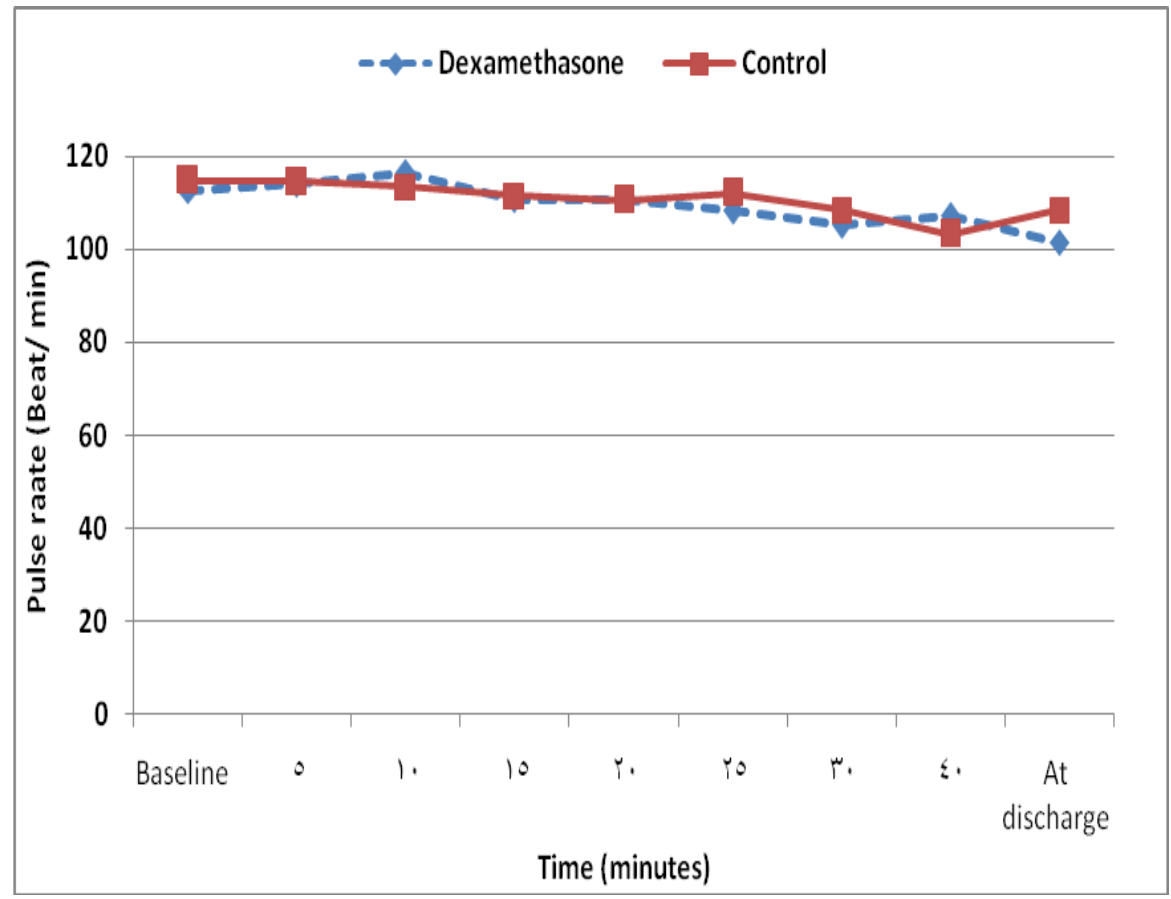

Figure (1): Mean pulse rate of both groups.

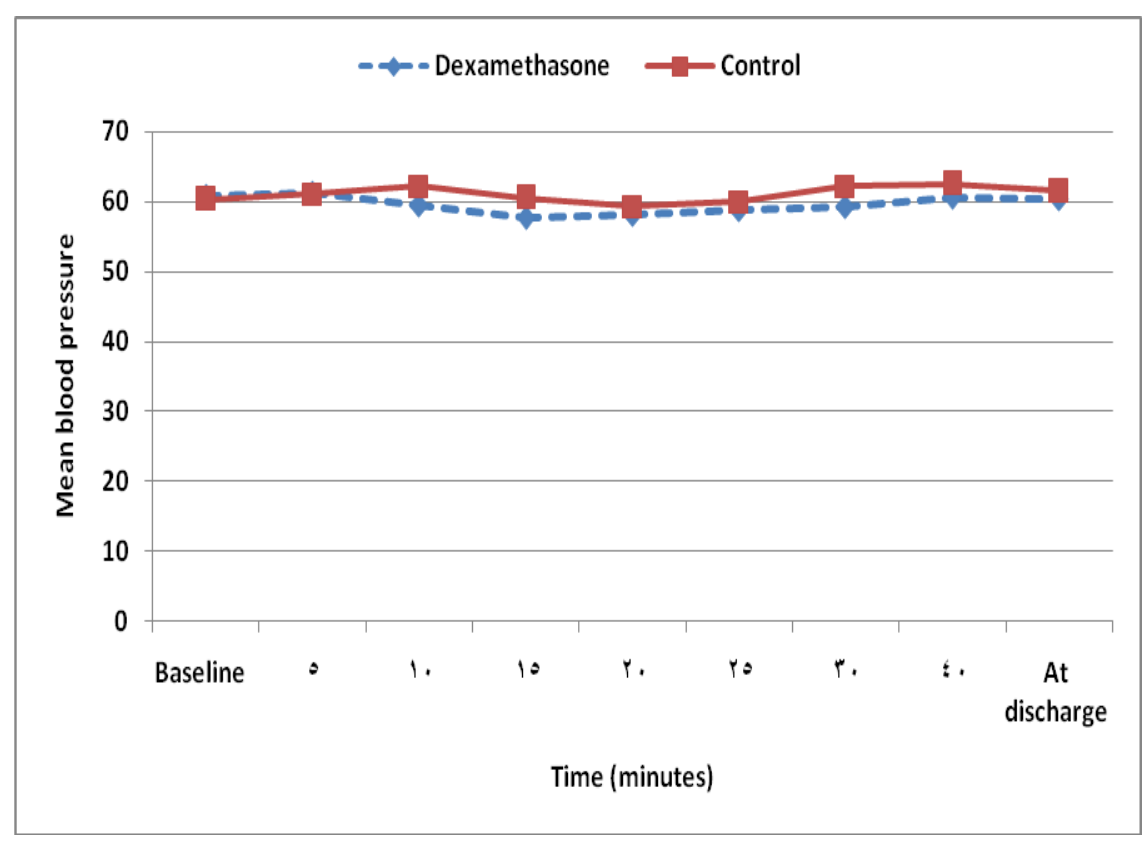

Figure (2): Mean arterial pressure of both groups. 
Postoperative analgesia was assessed regarding the postoperative pain score, duration of analgesia and analgesic requirements:

Regarding the pain assessment, pain was estimated using the FLACC pain score in both groups (Table 2). Results of our study of postoperative pain showed statistically significant differences in the post-anaesthesia care unit at the $1^{\text {st }}, 2^{\text {nd }}, 6^{\text {th }}, 18^{\text {th }}$ and $24^{\text {th }}$ hours. While, there was no statistically significant differences at $4^{\text {th }}$ and $12^{\text {th }}$ hours although it was lower in dexamethasone plus caudal group than in the caudal block alone group.

Table (2): FLACC pain score in both groups

\begin{tabular}{|c|c|c|c|c|c|}
\hline \multicolumn{2}{|c|}{ Time Group } & Mean & Std. Deviation & T test & P value \\
\hline \multirow[t]{2}{*}{$1 \mathrm{H}$} & $\mathrm{D}$ & 1.73 & 2.664 & \multirow{2}{*}{2.393} & \multirow{2}{*}{$\mathbf{0 . 0 2 0}$} \\
\hline & $\mathrm{C}$ & 3.03 & 1.326 & & \\
\hline \multirow[t]{2}{*}{$2 \mathrm{H}$} & $\mathrm{D}$ & 1.23 & 1.870 & \multirow{2}{*}{2.522} & \multirow{2}{*}{0.014} \\
\hline & $\mathrm{C}$ & 2.30 & 1.368 & & \\
\hline \multirow[t]{2}{*}{$4 \mathrm{H}$} & $\mathrm{D}$ & 1.03 & 1.810 & \multirow{2}{*}{0.085} & \multirow{2}{*}{0.933} \\
\hline & $\mathrm{C}$ & 1.00 & 1.174 & & \\
\hline \multirow[t]{2}{*}{$6 \mathrm{H}$} & $\mathrm{D}$ & 1.43 & 1.478 & \multirow{2}{*}{3.060} & \multirow{2}{*}{0.003} \\
\hline & $\mathrm{C}$ & .47 & .900 & & \\
\hline \multirow[t]{2}{*}{$12 \mathrm{H}$} & $\mathrm{D}$ & 2.50 & 1.570 & \multirow{2}{*}{1.891} & \multirow{2}{*}{0.064} \\
\hline & $\mathrm{C}$ & 3.27 & 2.661 & & \\
\hline \multirow[t]{2}{*}{$18 \mathrm{H}$} & $\mathrm{D}$ & 2.20 & 1.972 & \multirow{2}{*}{5.110} & \multirow{2}{*}{0.001} \\
\hline & $\mathrm{C}$ & 3.43 & 1.357 & & \\
\hline \multirow[t]{2}{*}{$24 \mathrm{H}$} & $\mathrm{D}$ & 3.40 & 2.621 & \multirow{2}{*}{1.922} & \multirow{2}{*}{0.048} \\
\hline & $\mathrm{C}$ & 5.37 & 4.850 & & \\
\hline
\end{tabular}

$\mathrm{D}=$ Dexamethasone $\quad \mathrm{C}=$ Caudal

Table (3): Comparison between dexamethasone group and control group as regards postoperative analgesia time (First time to require analgesia) $/ \mathrm{hrs}$

\begin{tabular}{|l|c|c|c|c|c|}
\hline & $\begin{array}{c}\text { Dexamethasone group } \\
\text { No. (\%) }\end{array}$ & $\begin{array}{c}\text { Control group } \\
\text { No. }(\%)\end{array}$ & Test & P & Sig \\
\hline $\begin{array}{l}\text { Post-operative } \\
\text { analgesia time }\end{array}$ & $\mathbf{1 1 . 3 5} \pm 2.36$ & $\mathbf{8 . 7 5} \pm 1.33$ & $\mathbf{t}=\mathbf{2 . 6 3}$ & $\mathbf{0 . 0 1}$ & $\mathrm{S}$ \\
\hline
\end{tabular}

Independent sample $\mathrm{t}$ test revealed that there was difference in duration of analgesia between the groups with $\mathrm{p}=$ 0. 01, which is statistically significant (Table 3)

Table (4): The total analgesic requirements by the two groups / 24 hours

\begin{tabular}{|l|c|c|c|c|c|}
\hline & $\begin{array}{c}\text { Dexamethasone } \\
\text { group }\end{array}$ & $\begin{array}{c}\text { Control } \\
\text { group }\end{array}$ & Test & P & Sig \\
\hline $\begin{array}{l}\text { Analgesic requirements } \\
\text { (paracetamol) } \\
\text { mg/24 hrs. }\end{array}$ & $\mathbf{4 3 0 ~} \mathrm{mg}$ & $\mathbf{6 8 0 m g}$ & $\mathbf{t}=\mathbf{2 . 9 3}$ & $\mathbf{0 . 0 0 2 4}$ & $\mathrm{S}$ \\
\hline
\end{tabular}

Regarding total analgesic requirements, there was significant difference between the two groups with dexamethasone group less (Table 4).

Table (5): The incidence of side effects between two groups

\begin{tabular}{|c|c|c|c|c|c|}
\hline & \multicolumn{2}{|c|}{ Group } & \multirow[b]{2}{*}{ Total } & \multirow[t]{2}{*}{ Chi square } & \multirow[t]{2}{*}{ P value } \\
\hline & D & $\mathrm{C}$ & & & \\
\hline \multirow[t]{2}{*}{ Failed } & 2 & 0 & 2 & \multirow{2}{*}{2.083} & 0.149 \\
\hline & $100.0 \%$ & $0.0 \%$ & $100.0 \%$ & & NS) \\
\hline \multirow[t]{2}{*}{ Hypotension } & 1 & 4 & 5 & \multirow{2}{*}{2} & 0.157 \\
\hline & $20.0 \%$ & $80.0 \%$ & $100.0 \%$ & & (NS) \\
\hline \multirow[t]{2}{*}{ Nausea } & 0 & 1 & 0 & \multirow{2}{*}{0} & 0.154 \\
\hline & $0.0 \%$ & $100.0 \%$ & $100.0 \%$ & & (NS) \\
\hline \multirow[t]{2}{*}{ Vomiting } & 0 & 1 & 0 & \multirow{2}{*}{2.083} & 0.132 \\
\hline & $0.0 \%$ & $100.0 \%$ & $100.0 \%$ & & $(\mathrm{NS})$ \\
\hline Total & 3 & 6 & 9 & 0.936 & $0.333(\mathrm{NS})$ \\
\hline
\end{tabular}

Using Chi square test.

Regarding the postoperative complications, there were no significant differences between the groups regarding postoperative nausea and vomiting (Table 5). 


\section{DISCUSSION}

Caudal block is one of the most common regional anesthetic techniques used in children. It is considered safe and simple procedure but its main disadvantage is its relatively short duration of action even with use of long acting agents such as bupivacaine ${ }^{(\mathbf{1 1})}$.

Steroids have a powerful anti-inflammatory action and have demonstrated to reduce pain and swelling after oral surgery, spinal surgery, and laparoscopic surgery. However, the exact mechanism by which dexamethasone may exert an analgesic effect is not fully understood. Systemic administration of steroids has been found to suppress tissue levels of bradykinin and the release of neuropeptides from nerve endings, both of which can enhance nociception in inflamed tissue. The established reduction in prostaglandin production might further contribute to analgesia by inhibiting the synthesis of the cyclooxygenase isoform-2 in peripheral tissues and in the central nervous system. They also inhibit other mediators of inflammatory hyperalgesia, for example, tumour necrosis factor-a, interleukin-17b and interleukin-6. Thus, despite the fact that the mechanism is not yet fully understood, a reduction in pain by steroids has been supported by many studies (12)

Dexamethasone, a corticosteroid with strong anti-inflammatory effects, provides postoperative analgesia and improvement in morbidity such as nausea, vomiting and fever. The clinical effects of dexamethasone are related to changes in the transcription of DNA to proteins and continue for some time after the drug is cleared from plasma. The plasma elimination half-life is only about $6 \mathrm{~h}$, and so there seems to be ongoing drug effects for a significant period of time after drug clearance from the plasma ${ }^{(13)}$.

Regarding demographic data, there were no significant differences between the two groups including age, height, weight of the patients, BMI and duration of surgery. Mean age of patients was 5.2 and 5.5 years in dexa group and control group respectively and mean weight of patients was $20.55 \pm 2.21$ in dexa group and $20.10 \pm 2.31$ in control group.

As regards hemodynamic data in our study, heart rate and mean arterial blood pressure were recorded at various intervals through intraoperative period. There was no significant difference between the two groups except in $25 \mathrm{~min}$ in heart rate and in 15 min in mean arterial BP where there were lower heart rate and mean arterial BP in dexa group. This is similar to that recorded Bharath et al. ${ }^{\text {(14). }}$.

In the present study, we used the FLACC score, which was the most suitable for pediatric pain assessment. FLACC score was lower in the caudal with i.v. dexamethasone group almost during the completely postoperative 24 hours than that in the caudal block alone. This comes in line with other studies, however they differ in the type of operations done and type of pain scoring used ${ }^{(13,14,15,17)}$.

The present study found that there was a significant difference in the duration of analgesia between both groups. Regarding the first time to require analgesia (paracetamol), the mean value of intravenous dexamethasone plus caudal group reported $11.35 \pm 2.36$ hours, which is more than that in caudal block alone (CB) $(8.75 \pm 1.33)$ hours. This agrees with other similar studies, which found that analgesia duration is significantly prolonged in pediatric patients who received intravenous dexamethasone with caudal block ${ }^{(15,16,17)}$.

The mechanism that dexamethasone may exert an analgesic effect is not fully understood. Systemic administration of steroids has been found to suppress tissue levels of bradykinin and the release of neuropeptides from nerve endings, both of which can enhance nociception in inflamed tissue. The established reduction in prostaglandin production might further contribute to analgesia by inhibiting the synthesis of the cyclooxygenase isoform-2 in peripheral tissues and in the central nervous system. They also inhibit other mediators of inflammatory hyperalgesia, for example, tumour necrosis factor-a, interleukin-17b, and interleukin-6.

Thus, despite the fact that the mechanism is not yet fully understood, a reduction in pain by steroids has been supported by many studies. In addition, dexamethasone may have a direct action on the nerve membrane that causes a local anesthetic effect, which augments the action of bupivacaine and prolongs its duration ${ }^{(7)}$.

As regards the analgesia consumption, our study showed that the total dose of analgesia administered (paracetamol in $\mathrm{mg} / 24 \mathrm{hrs}$ ) was less in i.v. dexamethasone than the caudal block group with mean values of $430 \mathrm{mg}$ versus $680 \mathrm{mg}$ respectively with a significant $p$ value of 0.0024 . Our results agree with other studies, which found that the total dose of postoperative analgesia (whatever) was significantly lower in dexamethasone than in caudal block group ${ }^{(\mathbf{1 8}}$, $19,20,21,22$ )

Considering the postoperative parameters, none of the children experienced any postoperative nausea and vomiting, which is matching with other studies. However the values were insignificant between the groups and there was no incidence of hypotension or bradycardia ${ }^{(6,23,24)}$. All children were able to tolerate oral intake well before being discharged. This may be due to minimal usage of intraoperative opioids (fentanyl), good pain relief by caudal block and effect of dexamethasone. In addition, we found no reports in the literature of complications from the use of a single dose of i.v. dexamethasone during pediatric surgery. 


\section{CONCLUSION}

Postoperative pain scores were lower in the dexamethasone group, while the incidence of adverse effects was similar in both groups. Intravenous dexamethasone $0.5 \mathrm{mg} / \mathrm{kg}$ in combination with a caudal block augmented the intensity and duration of postoperative analgesia without adverse effects in children undergoing hypospadias repair surgery.

\section{REFERENCES}

1. Silvani P, Camporesi A, Agostino $M$ et al. (2006): Caudal anesthesia in pediatrics: an update. Minerva Anestesiologica, 72: 453-459.

2. Samuel M, Hampson-Evans D, Cunnington $P$ (2002): Prospective to a randomized double-blind controlled trial to assess efficacy double caudal analgesia in hypospadias repair. Journal of Pediatric Surgery, 37: 168-174.

3. Khafagy H, Refaat A, El-Sabae H et al. (2010): Efficacy of epidural dexamethasone versus fentanyl on postoperative analgesia. J Anesth., 24: 531-6.

4. Hanasono M, Lalakea M, Mikulec A et al. (2004): Perioperative steroids in tonsillectomy using electrocautery and sharp dissection techniques. Arch Otolaryngol Head Neck Surg., 130: 917-21.

5. Hargreaves K, Costello A (1990): Glucocorticoids suppress levels of immunoreactive bradykinin in inflamed tissue as evaluated by microdialysis probes. Clin Pharmacol Ther., 48: 168-78.

6. Hong D, Byers M, Oswald R (1993): Dexamethasone treatment reduces sensory neuropeptides and nerve sprouting reactions in injured teeth. Pain, 55: 171-81.

7. Ferreira S, Cunha F, Lorenzetti B et al. (1997): Role of lipocortin-1 in the anti-hyperalgesic actions of dexamethasone. Br J Pharmacol., 121: 883-8.

8. Hong J, Han S, Kim W et al. (2010): Effect of dexamethasone in combination with caudal analgesia on postoperative pain control in day-case paediatric orchiopexy. Br J Anaesth., 105: 506-10.

9. Wong I, John-Green C, Walker S (2013): Opioidsparing effects of perioperative paracetamol and nonsteroidal anti-inflammatory drugs (NSAIDs) in children. Paediatr Anaesth., 23: 475-495.

10. Merkle S, Voepel-Lewis T, Shayevitz J et al. (1997): The FLACC pain score. Pediatric Nurs., 23: 293-297.

11. Rowney D, Doyle E (1998): Epidural and subarachnoid blockade in children. Anaesthsiology, 58: 980-1001.

12. Ferreira S, Cuncha F, Lorenzetti B (1997): Role of lipocortin-1 in the anti-hyperalgesia actions of dexamethasone. Br J Pharma., 121: 883-888.

13. Mohamed S, Ibraheem A, Abdelraheem M (2009): Preoperative intravenous dexamethasone combined with glossopharyngeal nerve block: Role in pediatric postoperative analgesia following tonsillectomy. Pediatric Anaesth., 266: 1815-1819.

14. Bharath S, Rakesh K, Sadik M et al. (2016): comparison of caudal and intravenous dexamethasone as adjuvant for caudal epidural block. Indian $\mathrm{J}$ of Anaesthesia, $26: 125-136$.

15. Bangash L, Afzal F, Hussain S et al. (2014): Comparison of caudal block alone with caudal block plus intravenous dexamethasone for postoperative analgesia in children undergoing orchidopexy under general anaesthesia. Biomedica, 30: 267-271.

16. Srinivasan B, Karnawat R, Mohammed S et al. (2016): Comparison of caudal and intravenous dexamethasone as adjuvants for caudal epidural block: A double blinded randomised controlled trial. Indian Journal of Anaesthesia, 60: 948-52.

17. Hong J, Han S, Kim W et al. (2010): Effect of dexamethasone in combination with caudal analgesia on postoperative pain control in day-case paediatric orchiopexy. British Journal of Anaesthesia, 105: 506510.

18. Sayed K, Amany M, Esam M et al. (2016): A new look for adding dexamethasone as an adjuvant to caudal bupivacaine. Pain Physician, 44: 23-88.

19. Dongare D, Karhade S (2017): Comparison of analgesic efficacy of caudal dexamethasone with intravenous dexamethasone as an adjuvant to caudal block in pediatric patients undergoing urogenital surgeries. Anesthesia, Essay and Researches, 11: 1009-13.

20. Desmet M, Braems H, Reynvoet M et al. (2014): IV and Perineural Dexamethasone are Equivalent in Increasing the Analgesic Duration of a Single-Shot Interscalene Block with Ropivacaine for Shoulder Surgery: A Prospective, Randomized, and Placebo-controlled Study. Survey of Anesthesiology, 58: 93-94.

21. Abd-Elshafy S, Yacoup A, Abdalla E et al. (2016): A new look on adding dexamethasone as an adjuvant to caudal bupivacaine; efficacy of postoperative pain and vomiting in pediatric patients. Pain Physician, 19: 841-852.

22. Abu Elyazed M, Eid G (2017): Dexamethasone versus neostigmine as an adjuvant to bupivacaine $0.25 \%$ for caudal analgesia in children undergoing open inguinal hernia repair. Egyptian Journal of Anaesthesia, 33: $283-$ 288.

23. Samarkandi H, Rana A, Musarat A et al. (2004): Use of dexamethasone to reduce postoperative vomiting and pain after pediatric tonsillectomy procedures. Saudi Medical Journal, 25 (11): 1636-9.

24. Bharath S, Rakesh K, Sadik M et al. (2016): Comparison of caudal and intravenous dexamethasone as adjuvant for caudal epidural block. Indian $\mathrm{J}$ of Anaesthesia, 26: 125-136. 